\title{
Lung Adenofibroma
}

National Cancer Institute

\section{Source}

National Cancer Institute. Lung Adenofibroma. NCI Thesaurus. Code C133091.

A very rare benign neoplasm that arises from the lung. It is characterized by the presence

of a stromal and an epithelial component. It resembles the adenofibromas that arise from the organs of the female reproductive system. 